\title{
USE OF THE TAX PRISM METHOD WHEN FORMING TAX PART OF THE BUDGET
}

\author{
Ludmila Verovska $^{1}$, Alexey Leontyev ${ }^{2}$ \\ ${ }^{1}$ Baltic International Academy, Latvia, ludmila.verovska@bsa.edu.lv \\ ${ }^{2}$ Baltic International Academy, Latvia, kratovo490@mail.ru
}

\begin{abstract}
The tax prism method is developed for the assessment of tax part of the budget as well as for forecasting the influence of tax optimisation on it. There are certain trends in global practice. Developing and transition economies are characterised by low tax burden. Economically developed countries with a high level of social security of population are characterised by high tax burden. The analytical and graphic-analytical research for the purpose of determination of optimum size of the taxation using the tax prism has been conducted. In addition to the concept of 'tax prism', concepts such as static and dynamic tax prisms have been introduced, allowing to consider changes in the part of the budget of interest in connection with a possibility of taxation subjects to reduce the size of a tax burden by various methods of tax optimisation, and also to consider the influence of other factors on it. The use of this approach helps effectively to enhance the tax legislation by modelling high-quality and quantitative consequences of one or another changes and innovations.
\end{abstract}

Key words: budget, taxation, tax optimization, tax burden, Laffer

JEL Classification: $\mathrm{H} 21, \mathrm{H} 22, \mathrm{H} 30$

\section{Introduction}

Now in many states of the world, the tax legislation is constructed so that it allows various subjects of entrepreneurship to search for optimal taxation variants to a varying degree. At the same time, there are no official techniques that are unambiguously regulating activities of private persons and legal entities in the field of taxation process improvement. General restrictions are set only by a framework of the legal framework.

In 1935, the judge J. Sanderlend expressed fundamental point of the U.S. Supreme Court, having declared that 'the right of taxpayers to avoid taxes ... using all means permitted by laws cannot be challenged by anybody' (Russel 2012).

Determination of tax types, purpose of their amount as well as planning of a tax filling part of the budget shall be carried out by taking into account the so-called 'taxation optimisation', that is, the reduction of the amount of paid taxes that doesn't contradict the legislation and carried out by taxation subjects.

The tax prism method, the concept that is shown in this article, can help government to improve tax planning policy. Such improvements can also help taxpayers to lower their tax burden. The task of this article is to introduce the theoretical aspects of the tax prism method. To complete the task, methods such as differentiation, graphical differentiation, mathematical and geometrical approach to the economic problems were used.

\section{Literature review}

So far, there is no methodology allowing to estimate qualitatively and quantitatively the influence of taxation optimisation on the tax part of the budget (Козинова, Ошарина 2010; Лагоша 2004; Ногин 2008; Черника 2010).

Effectual functioning of modern tax system is an overriding priority of any state. However, there is no 
unified solution for all states. The form of solution depends on many factors: the level of economic development of the country, adopted social policy, fiscal literacy and awareness of the population, the focus of national economy on short-term or long-term goals and so on.

Almost all currently made publications are related to the analysis of various methods of taxations and addressed to the taxpayers taxpayers (Mulhere et al. 2017; Astrinos 2017; Dlugosh, Vashchenko 2017; Lidings 2016). All of them aimed into the improvement of the financial conditions of enterprises and, at the same time, do not take into account the losses of the tax part of the budget as a result of the tax avoiding manipulations.

There are certain trends in global practice. Developing and transition economies are characterised by low tax burden. Economically developed countries with a high level of social security of population are characterised by high tax burden. The state, whose main purpose is the current budget revenue, raises taxes at the expense of economic development. A low quality of tax legislation, insufficient fiscal responsibility and literacy of the population promote tax evasion and the development of shadow economy. The totality of these factors affects the value of the tax burden.

\section{Methodology}

There are two kinds of tax burden: nominal and actual. The nominal tax burden is planned on the assumption that all tax payers will pay taxes and that they have to pay according to the existing legislation. The actual tax burden may differ from the nominal one on the value of tax evasion and shadow economy.

In specialised economic literature and practical activity, various methods for determining the value of tax burden are applied.

It is recommended to introduce the concept of tax prism for geometrical interpretation of forming of budget's tax part.

The tax prism is a geometrical figure whose amount corresponds to the amount of the taxes received by the state in the current (reporting) period and the side corresponds to the cumulative amount of taxes.

Considering square prism (Fig. 1), it is also filled with rectangular prisms of the smaller sizes whose volume corresponds to the contribution of each taxpayer.

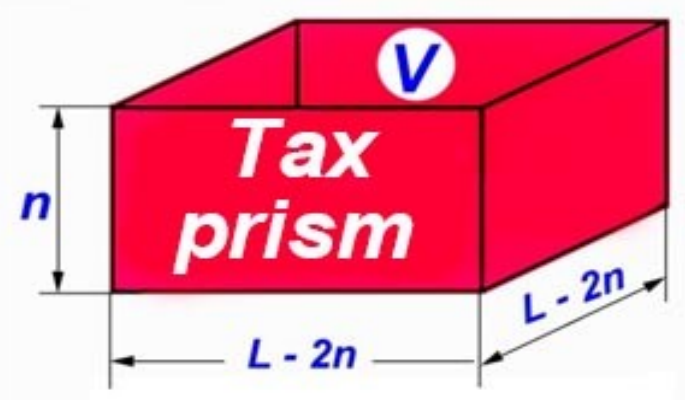

Fig. 1. The tax prism geometrical idea

On the one hand, the task of the state is to receive a maximum of taxes, from the other - not to put out of business the taxpayer, keeping his or her interest in profit earning by means of this type of activity. Therefore, the state shall also be engaged in taxation optimisation process.

This process can be considered by means of the offered tax prism.

For the creation of the prism, there is a page with the equal sides $L \times L$ (Fig. 2). 


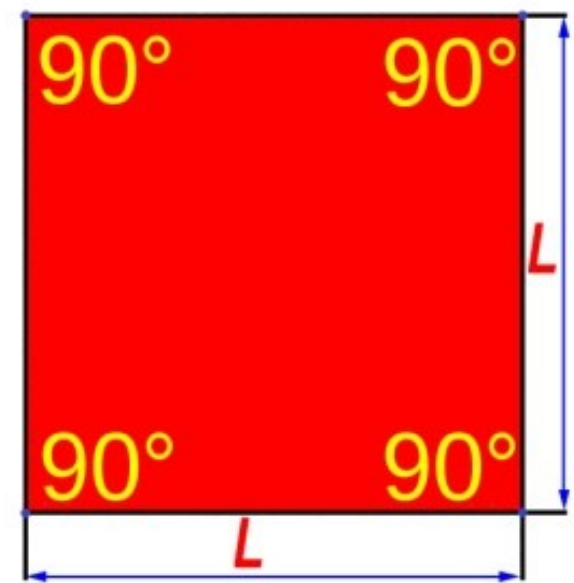

Fig. 2. Sample of the tax prism

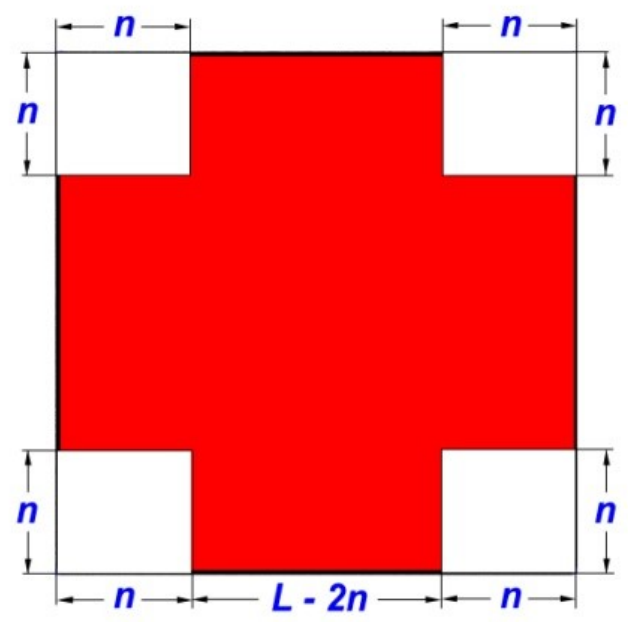

Fig. 3. The prism with cut off

The task of optimisation consists in making of it a hollow prism whose volume is equal to $V$ (where $V$ is the tax part of the state budget), having cut off a square of $n \times n$ size from each of four corners (Fig. 3 ), whereby $n$ is the general tax load established by the state for taxation subjects.

It is necessary to determine the size of the general tax burden $n$ which will correspond to the maximum size $V$.

$V$ can be displayed as function $n$. The area of the basis of a tax prism is equal to

$$
(L-2 n) \times(L-2 n) .
$$

The component of the state budget generated by taxes can be determined through the following expression:

$$
V=(L-2 n)^{2} n
$$

Value $n$ has to be big enough so that value $V$ would be maximum. However, it isn't necessary to go into extremes: when $n=0$ and $n=0.5 \mathrm{~L}$, budget will be zero. At these values of the general tax burden $n$, the tax prism won't exist because $n$ in geometrical interpretation represents prism height.

This can be considered on a conditional example. Let $L=12$. In this case, the tax part of the state budget will be equal to

$$
V=(12-2 n)^{2} n
$$

Then when $n=0$ and when $n=6$, the budget won't be filled.

The optimum size $V$ lies in the range bigger than zero but smaller than 6 . This range can be considered in integers.

In order to use the graphic approach, we visualise function $y=(12-2 n)^{2} n$ 
for $n$ values within the range from 1 to 6 (Fig. 4).

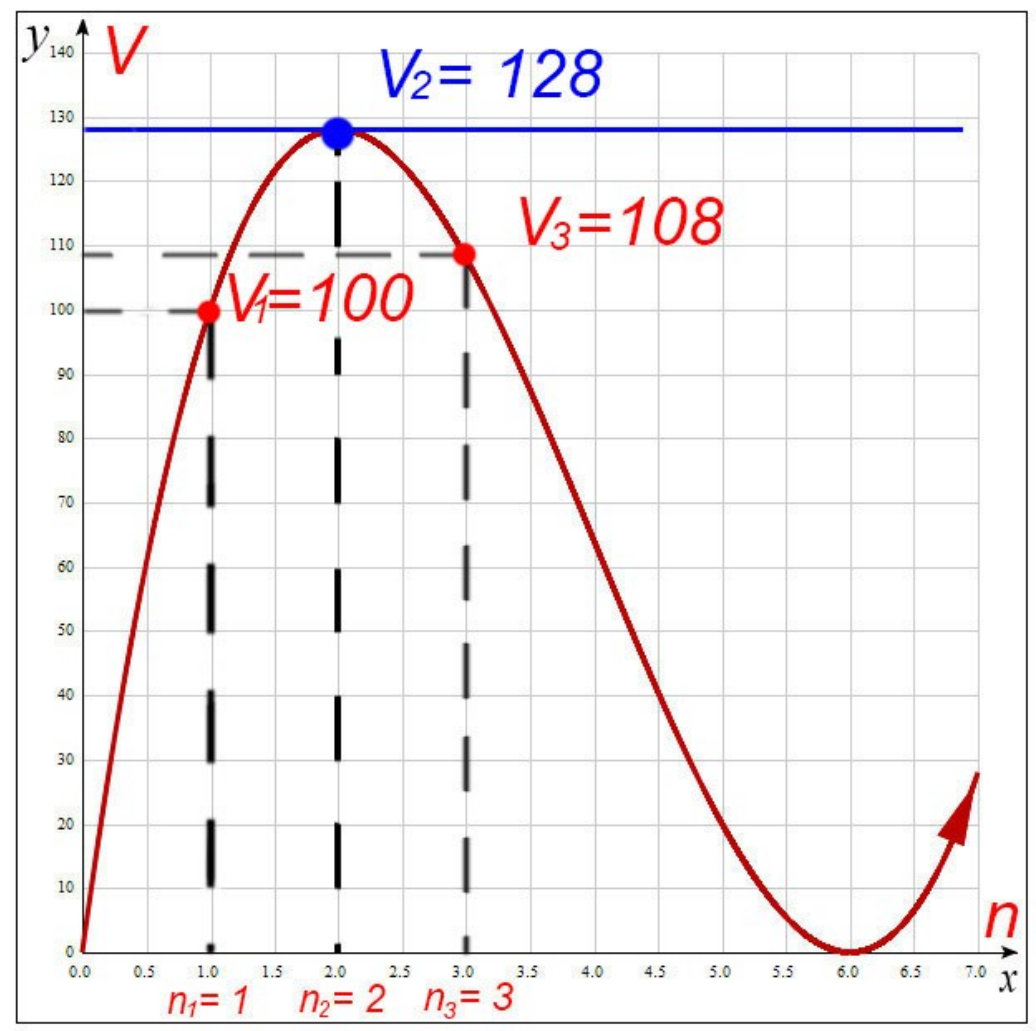

Fig. 4. Graphical visualisation of the function

If $n=1$, fill rate of the budget will be $y=100$; if $n=2$, fill rate of the budget will be $y=128$; if $n=3$, fill rate of tax part of the budget will be $y=108$. Value $n=2$ looks promising, but in the range of values from 1 to 3 , the other valid value can appear, which will correspond to the criterion of optimisation to a greater extent. It can be determined by analytical or graphic-analytical approaches.

Now differentiation of expression (3) can be carried out. For this purpose, we use the rule of the derivative multiplication:

$$
\begin{gathered}
\frac{d}{d x}(f(x) g(x))=f(x) \frac{d}{d x} g(x)+g(x) \frac{d}{d x} f(x) \\
f(x)=(-2 x+12)^{2} .
\end{gathered}
$$

Then we find $\frac{d}{d x} f(x)$, for what we execute replacement:

$$
\begin{gathered}
u=-2 x+12 \\
\left(u^{2}\right)^{\prime}=2 u .
\end{gathered}
$$

Then we multiply by $\frac{d}{d x}(-2 x+12)$, and differentiating $-2 x+12$ term by term, we get: 


$$
4 * 2 x-48
$$

$$
g(x)=x ; \text { will find } \frac{d}{d x} g(x)
$$

As a result: $x(4 * 2 x-48)+(-2 x+12)^{2}$.

After simplification, we finally get:

$$
12 x^{2}-96 x+144
$$

Now we can calculate equation roots:

$$
\begin{gathered}
y=12 x^{2}-96 x+144 \\
x_{1}=2 ; x_{2}=6 .
\end{gathered}
$$

Therefore, value $V=128$ at $n=2$ really is a maximum of a function (3).

In some cases, it is convenient to conduct the specified research using graphical-analytic approaches for descriptive reasons.

Graphical differentiation of a function diagram $y=(12-2 n)^{2} n$ must be carried out in order to determine an optimum combination of required size of the budget and the total tax load.

The method of graphical differentiation is based on geometrical interpretation of a derivative: the relation of an infinitesimal increment of a function to an infinitesimal increment of an argument on a graphics represents the tangent slope ratio against this curve in the considered point [3]:

$$
\operatorname{tg} \alpha_{i}=\frac{\overline{\Delta V}}{\overline{\Delta n}}
$$

Graphical differentiation can be executed by method of chords (Fig. 5). For this purpose, we divide the diagram of differentiable function $y=(12-2 n)^{2} n$ into identical areas with a step 0.5 (these areas are located between black points in Fig. 5) and draw chords by connecting the closest black points. The chord inclination angle with regard to abscissa axis matches a tangent inclination angle to our function diagram on the considered area. We place axes of coordinates under the function diagram in which we build a function diagram $\frac{d V}{d n}=f(n)$.

We set polar distance $H p$, taking into account the desirable vertical clearance of future diagram, and we designate a pole $P$. We draw the straight line parallel to the chord from a pole that connects two points limiting the specific area on which differentiation is carried out at the moment before it crosses the ordinate axis $\left(\frac{d V}{d n}\right)$. A straight line parallel to abscissa axis must've drawn from the obtained point before it crosses the straight line levelled down from the middle of a chord. The middle of chords are marked by lilac points in Fig. 5, which are designated by letters $a, b, c, d, e, f, g, h, i, j, k, l$.

Intersection points of the specified straight lines in Fig. 5 are marked by blue points and letters $a^{\prime}, b^{\prime}$ $, c^{\prime}, d^{\prime}, e^{\prime}, f^{\prime}, g^{\prime}, h^{\prime}, i^{\prime}, j^{\prime}, k^{\prime}, l^{\prime}$. 


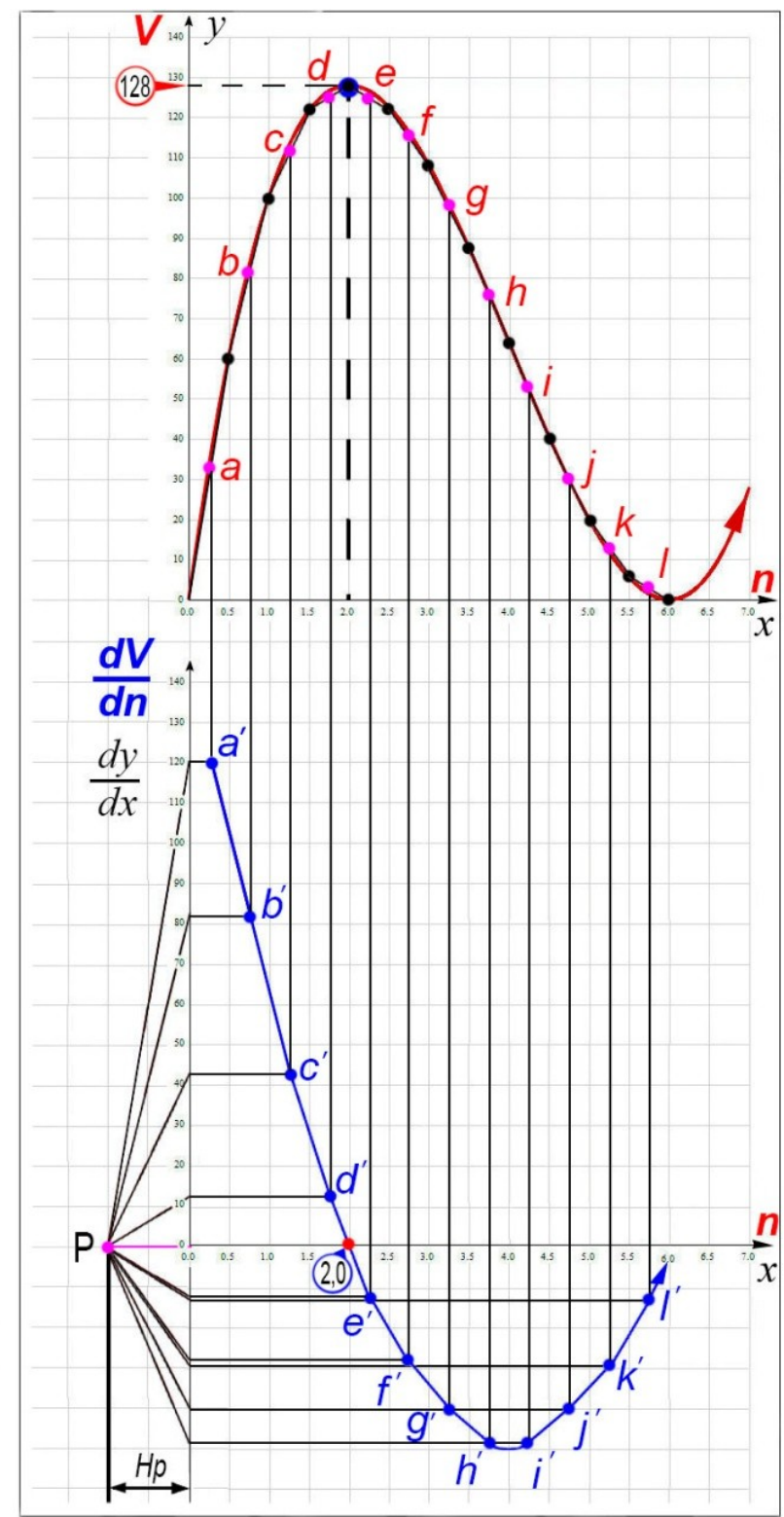

Fig. 5. Graphical differentiation of the function

As a result of differentiation, the parabola whose branches are directed to the up has been obtained. Parabola intersection points $\frac{d V}{d n}=f(n)$ with abscissa axis specify points of maximum and minimum of differentiable function. In the point corresponding to $n=2$, the function derivative (the lower diagram in Fig. 5) moves from positive area to negative, and the function changes from increase to decrease. Therefore, value of function when $n=2$ is its maximum.

The horizontal tangent will pass through a point in which function $y=(12-2 n)^{2} n$ will reach the maximum value (it is shown in Fig. 4).

To the left from a maximum function $V=f(n)$ grows; to the right, it decreases. On the left, the value of its inclination is positive; on the right, it is negative. In the most upper point, nothing occurs. Therefore, it is possible to draw horizontal (i.e. with a zero inclination) tangent (Fig. 4). It will also be optimum value of the total tax load of $n$ giving the maximum value of assignments $V$ to the state budget in case of which interests of taxpayers are observed.

It is obvious that the studied function has two extrema because the parabola, received by differentiation, crosses abscissa axis in two points. Therefore, when solving similar tasks, it is 
necessary to stipulate that the positive maximum of function shall be found. In our case, when tax value $n=6$ production will become equal to zero, that will lead to zero the size of a tax part of the state budget as it was stated above; when $n=0.5 L$, tax prism doesn't exist. For our case, when $L=12$, this value is equal to $n=0.5 \mathrm{~L}=6$.

It should be noted that on the falling part of function $V=f(n)$ located more to the right of maximum point, sharp reduction of business activity occurs. It should be noted that withdrawal of more than $50 \%$ of the income in the form of tax extremely negatively affects the initiative of entrepreneurs and completely blocks production expansion. At the same time, entrepreneurs begin to look for an opportunity to reduce the amount of the taxes withdrawn by the state by both legal and illegal methods. So far, exact threshold value of an effective rate in case of which occurs destruction of business activity isn't found. However, Laffer's concept states that in case of a tax burden of more than $35-40 \%$, the entrepreneur gets to 'a tax trap' and thinks of advantage of the business [2].

\section{Results}

As the tax prism (Fig. 1) is filled with prisms of the smaller size whose volume corresponds to quantity of the taxes paid by each subject of the taxation, then optimisation of the taxation leads to reduction of its sizes. It is offered to introduce the concept of a static and dynamic tax prism accounting for the decrease in the amount of the collected taxes because of the use of legal tax optimisation schemes by the taxpayers. Static tax prism is a prism whose amount of $V_{s t}$ is interpreted as a tax part of the budget without possible tax optimisation. Dynamic tax prism is a prism whose amount of $V_{d y n}$ is interpreted as a tax part of the budget by taking into account the possible tax optimisation.

$$
V_{d y n}=k_{t o} V_{s t}
$$

where $k_{t o}$ - coefficient of tax optimization $\left(k_{t o} \leq 1\right)$.

When $k_{t o}=1$, taxpayer didn't take actions directed to tax reduction, using methods of tax optimisation. When $k_{t o}<1$, such actions were taken.

Therefore, when taxpayers use tax optimisation, the dynamic volume of a tax prism will be less than static: $V_{d y n}<V_{s t}$

This model takes into consideration not only the possible tax optimisation but also some other factors influencing the tax part size of the budget.

For this purpose, it is necessary to enter the corresponding raising or decreasing coefficients into formula (12).

\section{Conclusions}

The use of the concept 'tax prism' and its division on static and dynamic versions allows to visualise the process of taxation optimisation that is carried out by state authorities in case of establishment of types and determination of the amount of taxes in both short-term and long-term periods, to make it more exact. The use of this approach helps effectively to enhance the tax legislation by modelling high-quality and quantitative consequences of one or another changes and innovation.

Herein introduced the theoretical concept of the tax prism. Practical researches can only be carried out on macroeconomics scale. At present, such researches are happening, but they require a widest amount of data processing. The concept of the tax prism can also be used to find illegal tax avoidance in the whole economy of the country as well as in different sectors of the economy. With future improvements, herein introduced the method that can also make able to find even separate economy 
units, who illegally avoid all or partly meant-to-pay taxes (here meant mainly all illegal avoidance that cannot be easily found by government structures with currently existing methods).

\section{References}

J. Dlugosh, M. Vashchenko. (2017). THE WAYS OF ILLEGAL OBTAINING VAT IN POLAND [Accessed 30.03.2017]. Available from Internet: http://www.ed.ksue.edu.ua/ER/EER/documents/blog.php?tag=fictitious+export

Jsse Russell, Ronaldm - Cohn Supreme Court of the United States. - Book on Demand Ltd. 2012. - 571 p.

Kaitlin Mulhere, Elizabeth O’Brien, Kerri Anne Renzulli, Taylor Tepper, Penelope Wang ,Martha C. White. (2017). 33 Smart Ways to Cut Your Taxes Right Now [Accessed 09.03.2017]. Available from Internet: http://time.com/money/4657974/cut-your-taxes-2016-2017/

Laffer Arthur B ; Jan P Seymour The economics of the tax revolt, New York [u.a.] : Harcourt Brace Jovanovich, $1979,138 \mathrm{p}$.

Lidings (2016). Новый ориентир для налоговой оптимизащии: по материалам «дела Орифлэйм». [Accessed 15.03.2017]. Available from Internet: http://www.lidings.com/eng/articles2\%3Fid\%3D5?id=108

Mark Astrinos. (2017). Reducing investment taxes in 2017 [Accessed 12.03.2017]. Available from Internet: http://www.journalofaccountancy.com/newsletters/2017/feb/reducing-investment-taxes-2017.html

Taxadviser (2017). [Accessed 02.04.2017]. Available from Internet: http://www.taxadvisermagazine.com/

Головнин Д. Н., Графическая математика, М. - Л., 1931г., -216с.

Козинова А.Т., Ошарина Н.Н. Экономико - математические модели: Учебное пособие. - Нижний Новгород: Нижегородский госуниверситет, 2010. - 73 с.

Лагоша Б.А. Оптимальное управление в экономике: Учебное пособие. / Московский государственный университет экономики, статистики и информатики - М., 2004. - 133 с.

Ногин В.Д. Введение в оптимальное управление. Учебно-методическое пособие. - СПб: Изд-во «ЮТАС», 2008 г., -92 c.

Черника Д.Г. Введение в экономико-математические модели налогообложения: Учеб. пособие / М.: Финансы и статистика, 2010. - 256 с. 